\title{
Research on EPDM Matrix Nonlinear Insulation Composites
}

\section{Changming $\mathrm{Li}^{1^{*}}$, Qinglang Chen ${ }^{1}$, Chunpeng Yin ${ }^{1}$, Baozhong Han ${ }^{1,3}$}

$\left({ }^{1}\right.$ Key Laboratory of Engineering Dielectric and its Application, Ministry of Education, Harbin University of Science and Technology, Harbin, 150080; ${ }^{2}$ Chengde Power Supply Company, State Grid Jibei Electric Power Company Limited, Chengde, 067000; ${ }^{3}$ Shanghai Qifan Wire and Cable Co., Ltd., Shanghai, 200008)

Corresponding Author: Changming Li

Keywords: EPDM; Nonlinear electrical conductivity; Breakdown strength; HVDC; Cable accessory

\begin{abstract}
In order to develop non-linear material used for the reinforced insulation in HVDC cable accessory, non-linear EPDM composites were fabricated by adding conductive nano fillers to improve the conductivity characteristic of EPDM. The conductivity and the DC breakdown strength of composites were tested under $25{ }^{\circ} \mathrm{C}$ and $70{ }^{\circ} \mathrm{C}$, respectively. The influences of types, portions and compounds of nano inorganic fillers on the conductivity were researched and the results indicated that after adding proper portion of nano $\mathrm{SiO}_{2}$, the mechanical properties of EPDM were improved. Adding nano SiC, carbon black and graphite could make the nonlinear electrical conductivity better. Adding nano SiC, carbon black and graphite all could make a great influence on the breakdown strength of composite material.
\end{abstract}

\section{Introduction}

HVDC cable has many advantages such as low loss, large transmission capacity, unrestricted transmission distance, high operational stability coupled with the ability to connect asynchronous power grids etc. Its application plays a more and more important role in real life ${ }^{[1-3]}$.With HVDC technology developing day by day, XLPE insulated HVDC cable not only maintains the absolute superiority in connecting the mainland power grid across the wide strait, but also expands the application in the interconnection of asynchronous onshore grids, isolated load transmission, increase of metropolitan power capacity, transmission of renewable energy, and other aspects ${ }^{[4-7]}$.

Cable accessories are regarded as an important part of the cable system and the weakest part of the line. According to statistical results, the failure of cable accessories takes up $70 \%$ of the total. Compared with plastic insulated AC cable accessories, the production of DC cable accessories is more difficult, which is mainly because its electric field distribution is more complex. Besides, the surface between the cable insulation and the accessories easily enhances the accumulation of space charge, which may lead to serious distortion of the electric field distribution ${ }^{[8-10]}$. Under DC voltage, the electrical conductivity properties of XLPE insulation commonly used in high-voltage DC cable will drastically change with temperature and electric field, and meanwhile, the change of electrical conductivity of ordinary silicon rubber or ethylene propylene rubber under the same condition is small, which leads to two orders of magnitude difference between the conductivity of XLPE and rubber $^{[11]}$. As the DC field in the composite insulation distribute as the resistance, when ordinary rubber is used as reinforced insulation for DC cable accessory, its internal electric field distribution may be seriously uneven, so the accessories insulation is easy to breakdown.

A large number of research shows nonlinear dielectric material can be fabricated by adding micro and nano inorganic fillers such as zinc oxide, barium titanate and silicon carbide to polymer insulation. Since the nonlinear conductivity and dielectric constant of the non-linear insulation material significantly increase with the electric field in a certain range, it has a great ability in homogenizing the electric field distribution. Boettcher B, Daniel W and other experts used silicone rubber with nonlinear conductivity fabricated by adding pressure-sensitive zinc oxide as the material of stress control body, and then the electric field distribution at the end of insulation shielding was obviously improved [12]. Studies reported that ABB company had developed a 
HVDC cable joint consisting of a nonlinear material layer, and it could keep the similar electrical conductivity and dielectric constant with XLPE and silicone rubber under running temperature rise and temperature gradient, which ensured uniform electric field distribution, inhibited the generation of space charge and greatly improved the long running reliability of HVDC cable line [13]. In this paper, nanocomposites were fabricated by adding nano-SiC, graphite and carbon black to EPDM. The conductivity and DC breakdown strength of the composites were studied to explore and develop nonlinear insulation material suitable for reinforced insulation in HVDC cable accessories.

\section{Experimental Method}

\subsection{Materials}

EPDM was obtained from U.S.A. Nano $\mathrm{SiO}_{2}$ has an average diameter of $12 \mathrm{~nm}$ and a specific surface area of about $200 \mathrm{~m}^{2} / \mathrm{g}$. Nano SiC has an average diameter of $40 \mathrm{~nm}$. Carbon black- 1 has an average diameter of $47 \mathrm{~nm}$ and a specific surface area of about $48 \mathrm{~m}^{2} / \mathrm{g}$. Carbon black-2 has an average diameter of $95 \mathrm{~nm}$ and a specific surface area of about $20 \mathrm{~m}^{2} / \mathrm{g}$.

\subsection{Experiment Equipment}

Tab.1 Main equipment

\begin{tabular}{c|c|c}
\hline Name of Equipment & Number & $\begin{array}{c}\text { Place of } \\
\text { Production }\end{array}$ \\
\hline Open Mixer & XL-157/345 & Harbin \\
\hline Plate Vulcanizing Machine & XLB25-D & Huzhou \\
\hline Vacuum Drying Oven & DZ-3BC & Tianjin \\
\hline Material Universal Testing Machine & CMT & Shenzhen \\
\hline Electro-thermal Blowing Dry Cabinet & $101-2 A B$ & Tianjin \\
\hline Tablet Punching Machine & CP-25 & Shanghai \\
\hline Pico Ammeter & EST122 & Beijing \\
\hline HVDC Power Supply & HB-Z103-2AC & Tianjin \\
\hline
\end{tabular}

\subsection{Sample Preparation}

EPDM and nano fillers were mixed evenly according to the designed proportions using an open mixer. A suitable amount of EPDM matrix composites was put in the mould and molded using a plate vulcanizing machine, and then kept for $30 \mathrm{~min}$ at $175{ }^{\circ} \mathrm{C}$ and $15 \mathrm{MPa}$ to ensure that the materials were fully vulcanized. After cooling down under the same pressure, aluminum foil electrodes were pasted respectively on both sides of the sample according to the requirements of three electrodes test. The test electrode radius was $25 \mathrm{~mm}$, the inner and outer radius of the protect electrodes were $27 \mathrm{~mm}$ and $37 \mathrm{~mm}$, respectively, and the radius of $\mathrm{HV}$ electrode is $37 \mathrm{~mm}$.

\subsection{Dielectric Property Test}

Electrical Conductivity Test: Samples were placed in the shielding box and connected with a power supply and a pico-ammeter through the electrodes. Firstly the temperature of the shielding box was set as $25{ }^{\circ} \mathrm{C}$, the voltage was applied to the sample from low to high with the maximum voltage up to $10000 \mathrm{~V}$, and the current through the sample were recorded. Then the temperature of the shielding box was set as $70{ }^{\circ} \mathrm{C}$, and the same procedures as above were repeated orderly.

DC Breakdown Strength Test: Standard cylindrical electrodes were used. The diameter of high voltage is $25 \mathrm{~mm}$, the rising rate of voltage is about $1 \mathrm{kV} / \mathrm{s}$, and the thickness of the sample and the breakdown voltage were recorded. The output voltage of HVDC generator was from $0 \mathrm{kV}$ to $60 \mathrm{kV}$. 


\section{Results and Discussion}

\subsection{The influence of nano $\mathrm{SiO}_{2}$ content on mechanical properties of EPDM}

The tensile strength and elongation of pure EPDM is low, and nano $\mathrm{SiO}_{2}$ was added to improve the mechanical properties. $2.8 \mathrm{phr}$ DCP, $1 \mathrm{phr}$ stearic acid, 5phr $\mathrm{ZnO}$ and different fractions of nano $\mathrm{SiO}_{2}$ were added into $100 \mathrm{phr}$ EPDM, respectively. Then the mechanical properties of different materials were tested and shown in Fig.1 and Fig.2.

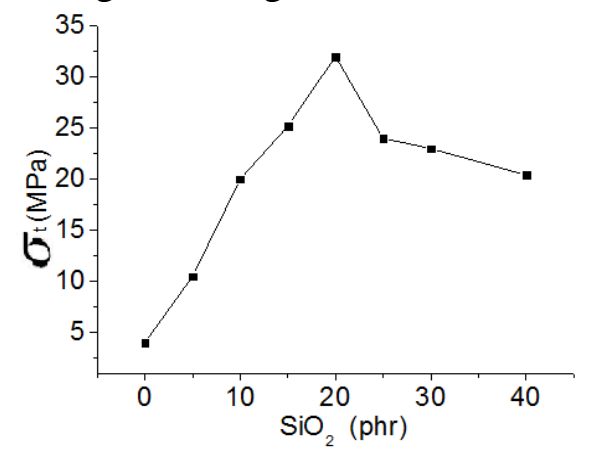

Fig.1 The relationship between $\mathrm{SiO} 2$ content and tensile strength of EDPM matrix composites

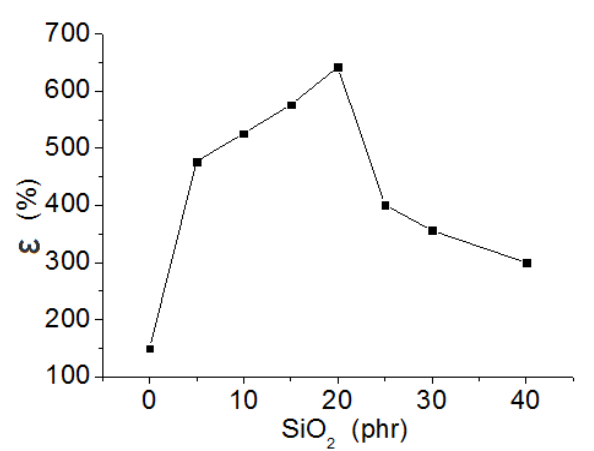

Fig.2 The relationship between SiO2 content and elongation of EDPM matrix composites

As shown in Fig.1 and Fig.2, the tensile strength and elongation of EPDM matrix composites increased with increasing nano $\mathrm{SiO}_{2}$ content when the nano $\mathrm{SiO}_{2}$ content was less than 20 phr. And then as the nano $\mathrm{SiO}_{2}$ content further increased, the tensile strength and elongation of EPDM matrix composites had a tendency to decrease.

\subsection{Conductivity properties of EPDM matrix composites}

(1) The influence of SiC content on the conductivity of EPDM matrix composites

The conductivity of EPDM matrix composites with different fractions of nano $\mathrm{SiO}_{2}$ was tested firstly, and the results were shown in Fig.3. As a whole, the conductivity of composites had the same variation trend at $25{ }^{\circ} \mathrm{C}$ and $70{ }^{\circ} \mathrm{C}$. The conductivity of the composite decreased at first and then increased with the increasing dosage of nano $\mathrm{SiO}_{2}$. But the conductivity of each material was less affected by the change of the electric field strength. The results also showed that as the testing temperature increased, the conductivity of EPDM matrix composites obviously increased. 


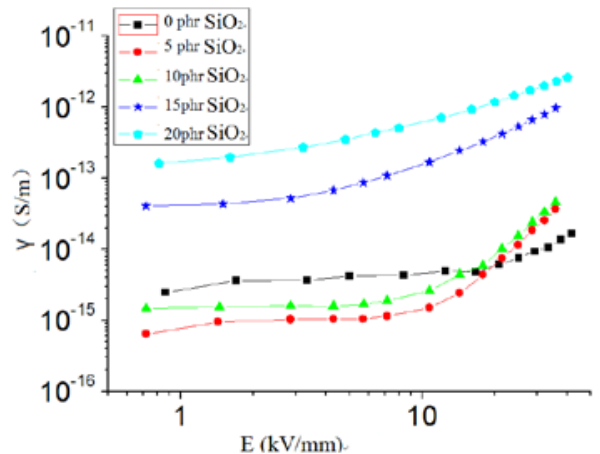

a) $25 \mathrm{oC}$

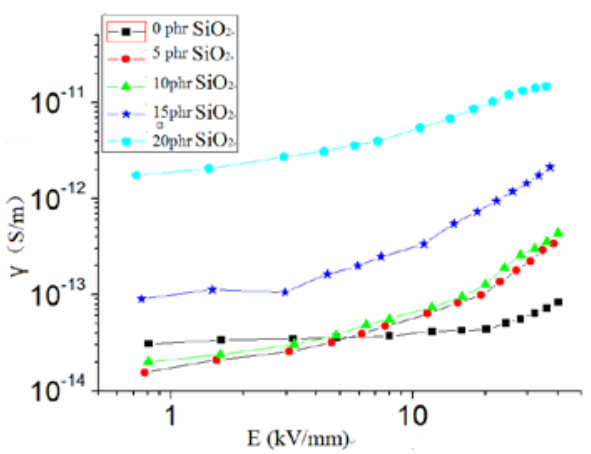

b) $70 \mathrm{oC}$

Fig.3 The conductivity properties of EPDM matrix composites

The early results indicated that nano $\mathrm{SiC}$ can improve the nonlinear conductivity properties of polymer insulation. Therefore, different fractions of nano-SiC were added in the EPDM matrix composites with better mechanical properties added with $20 \mathrm{phr}$ nano $\mathrm{SiO}_{2}$. The conductivities of different materials were shown in Fig.4.

From Fig.4, the conductivity of EPDM matrix composites increased with the rising of electric field strength and temperature. When the temperature rose from $25^{\circ} \mathrm{C}$ to $70{ }^{\circ} \mathrm{C}$, the conductivities of each composite increased about one order of magnitude under the electric field strength of about 0.8 $\mathrm{kV} / \mathrm{mm}$. With the increase of SiC content, the conductivity of EPDM matrix composites decreased firstly and then increased. When the content of nano $\mathrm{SiC}$ was from $5 \mathrm{phr}$ to $40 \mathrm{phr}$, the conductivity of each sample was lower than that of sample without nano $\mathrm{SiC}$ under the different electric field strength. When the $\mathrm{SiC}$ contents were $50 \mathrm{phr}$ and $60 \mathrm{phr}$, the conductivity of the samples were also lower than that of the sample without nano $\mathrm{SiC}$ under low electric field strength. At $25{ }^{\circ} \mathrm{C}$, when the electric field strength was higher than $17 \mathrm{kV} / \mathrm{mm}$, the conductivity of the samples increased rapidly nonlinearly. The results above suggested that when the additive amount of nano SiC was large, the nonlinear conductivity properties of EPDM matrix composites can be improved.

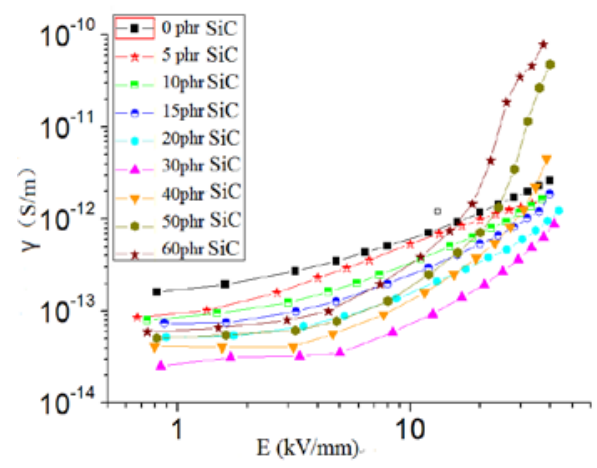

a) $25 \mathrm{oC}$

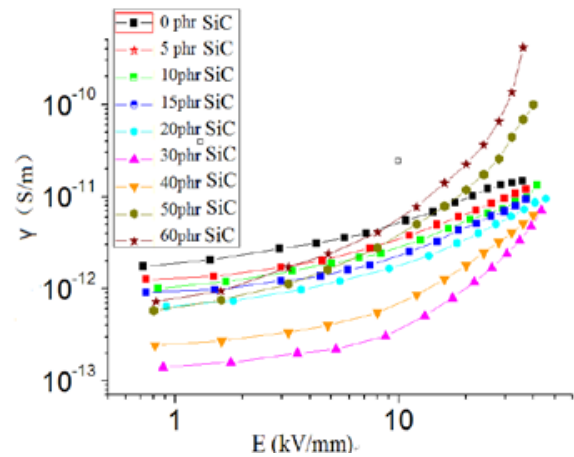

b) $70 \mathrm{oC}$

Fig.4 The conductivity properties of EPDM matrix composites filled with nano SiC

(2) The influence of nano conductive materials on the conductivity of EPDM matrix composites

Since the excessive addition of nano $\mathrm{SiC}$ would deteriorate the other properties of the composites, nano conductive materials were used as the filler instead of a portion of nano SiC to improve the conductivity properties. Two kinds of the carbon black and one kind of graphite were chosen as nano fillers. 40 phr nano SiC and 5 phr or 3 phr nano conductive fillers were added in EPDM. The conductivity properties of each material were shown in Fig.5 and Fig.6. 


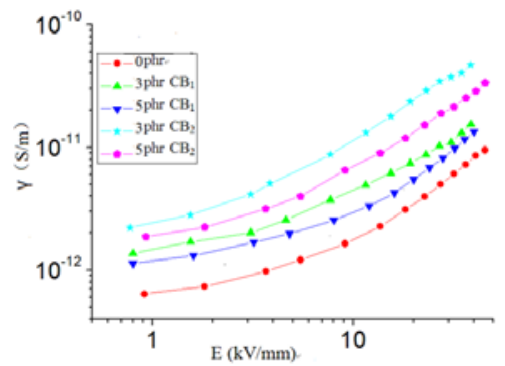

a) $25 \mathrm{oC}$

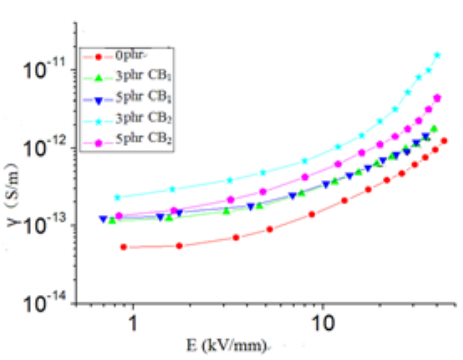

b) $70 \mathrm{oC}$

Fig.5 Conductivity properties of EPDM matrix composites filled with nano carbon black

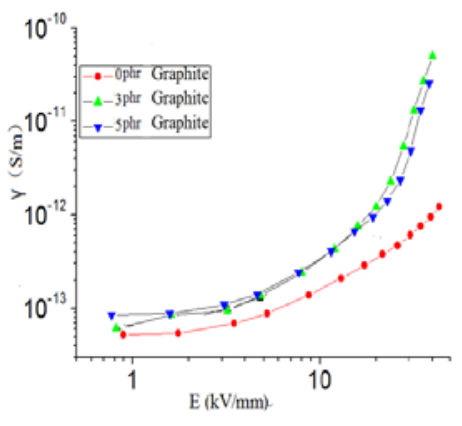

a) $25 \mathrm{oC}$

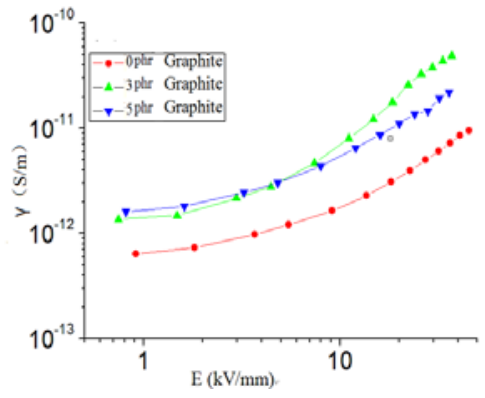

b) $70 \mathrm{oC}$

Fig.6 Conductivity properties of EPDM matrix composites filled with nano graphite

The above experiment results showed that when using the same kind of carbon black, the conductivity of EPDM matrix composites increased with the increase of carbon black content. When the content of carbon black was the same, the nonlinear conductivity properties of EPDM matrix composites filled with nano carbon black 2 were better than that of the material filled with carbon black 1. Nano graphite can improve the conductivity properties of EPDM matrix composites, but the content of nano graphite had a little impact on the conductivity of the composite.

\subsection{The influence of nano materials on DC breakdown properties of EPDM matrix composites}

1) The influence of nano $\mathrm{SiO}_{2}$ and $\mathrm{SiC}$ on DC breakdown properties of EPDM matrix composites

The DC breakdown strength of samples filled with nano- $\mathrm{SiO}_{2}$ and nano-SiC above mentioned was tested at $25{ }^{\circ} \mathrm{C}$ and $70{ }^{\circ} \mathrm{C}$. Ten specimens of each sample were tested. Since the experimental data of different specimens was dispersive, Weibull distribution statistics was used to calculate the breakdown strength of the material. The experimental results were shown in Fig.7 and Fig.8.

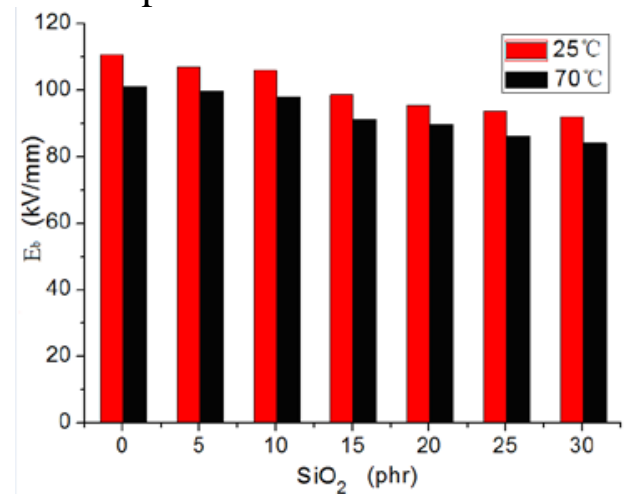

Fig.7 The DC breakdown strength of EPDM matrix composites filled with nano-SiO2 


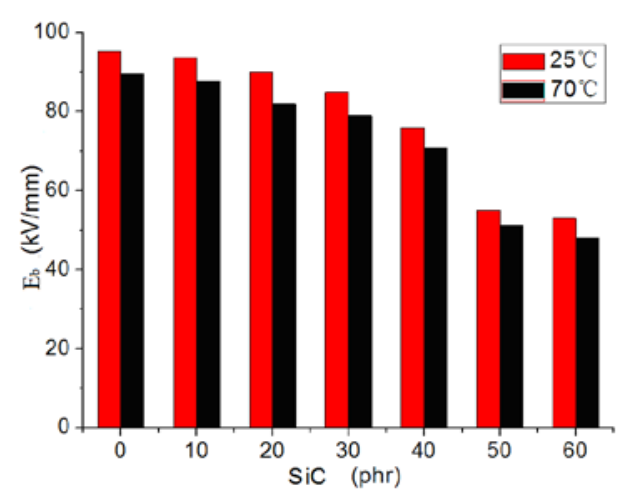

Fig.8 DC breakdown strength of EPDM matrix composites filled with nano $\mathrm{SiO} 2$ and nano $\mathrm{SiC}$

From Fig.7, the breakdown strength of EPDM matrix composites at $25{ }^{\circ} \mathrm{C}$ was higher than the results tested at 70 oC. When the content of nano $\mathrm{SiO}_{2}$ increased from 0 phr to $30 \mathrm{phr}$, the DC breakdown strength of EPDM matrix composites fell by $16.8 \%$ at $25{ }^{\circ} \mathrm{C}$ and $16.7 \%$ at $70{ }^{\circ} \mathrm{C}$. In general, the addition of nano $\mathrm{SiO}_{2}$ had little impact on the DC breakdown strength of EPDM matrix composites. From Fig.8, when the content of nano SiC was greater than 20 phr, the DC breakdown strength of EPDM matrix composites obviously decreases with the increase of nano SiC content, and the breakdown strength fell more rapidly when nano SiC content exceeded 40 phr.

2) The influence of carbon black and graphite on DC breakdown strength of EPDM matrix composites

The DC breakdown strength of EPDM matrix composites filled with carbon black and graphite were shown in Fig.9.

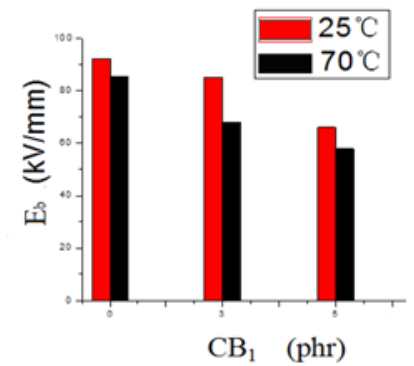

a) carbon black 1

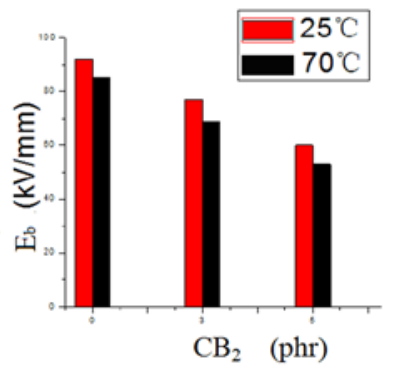

b) carbon black 2

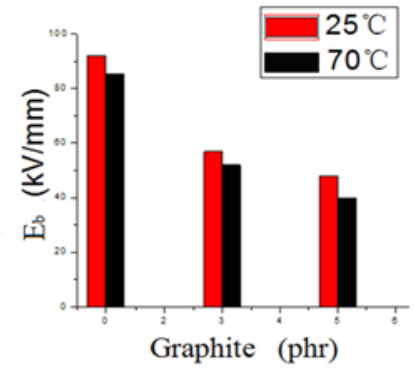

c) nano graphite

Fig.9 DC breakdown strength of EPDM matrix composites filled with nano conductive materials

As shown in Fig.9, the breakdown strength of each material at $25{ }^{\circ} \mathrm{C}$ was higher than the results tested at $70^{\circ} \mathrm{C}$. With the increase of carbon black and graphite content, the DC breakdown strength of EPDM matrix composites decreased. When the content of carbon black and graphite was the same, the composite filled with nano graphite had the lowest DC breakdown strength and the material filled with nano carbon black 2 was secondary.

\section{Conclusion}

(1) With the increase of nano $\mathrm{SiO} 2$ content, the tensile strength and elongation increased firstly and then decreased in tendency, and the conductivity decreased firstly and then increased.

(2) The conductivity of EPDM matrix composites decreased firstly and then increased with the increase of $\mathrm{SiC}$ content. When the content was larger than $40 \mathrm{phr}$, the nonlinear conductivity of EPDM matrix composites grew rapidly under the electric field strength exceeding $17 \mathrm{kV} / \mathrm{mm}$.

(3) With the increase of carbon black content, the conductivity of EPDM matrix composites filled with the same kind of carbon black increased. The improvement of the conductivity properties introduced by carbon black 2 was better than that of carbon black 1 .

(4) With the increase of nano $\mathrm{SiO}_{2}, \mathrm{SiC}$, carbon black and graphite content, the breakdown strength of EPDM matrix composites decreased. The impact of nano $\mathrm{SiO}_{2}$ was minimal, the impact of nano SiC was little larger and the impact of nano conductive materials was the largest. 


\section{Acknowledgment}

The authors thank National Science Foundation of China (grant No. 51337002) and Natural Science Foundation for Distinguished Young Scholars of Heilongjiang Province (JC201409).

\section{References}

[1] Zeng Nanchao. The Applications of HVDC in Electric Grid in China [J]. Technical of High Voltage, 2004, 30(11):1-12

[2] Wen Jialiang, Wu Yue, Peng Yang, etc. The Analysis about Prospect of DC Electric Grid in China [J]. Proceedings of the CSEE, 2012, 32(13):7-12

[3] Xu Mingzhong, Zhao Hong, Ji Chao, etc. Preparation and Property of Space Charge of MgO/LDPE Nano composite material [J]. Technical of High Voltage, 2012, 38(3): 684-690

[4] Volker Wendt. Future of Electric Grid in Europe [C]. Memoir of academic conference of the Wire and Cable Branch of Chinese Electrotechnical society in 2011, Fuzhou, 2011.11.10-13:24-32.

[5] Jacobson B, De Toledo P F, Aspklund G. 500 MW City Center Infeed with Voltage Source Converter Based HVDC [C].40th Meeting of Study Committee B4 and Collokium on Role of HVDC, FACTS, and Emerging Technologies in Evolving Power Systems, July 1, 2005, Bangalore, India: 1-10.

[6] Zhang Linshan, Yang Qing, Cui Yufeng, etc. Applications of Flexible Cable in DC Transmission in Urban Electric Grid [J]. Yunnan Power Electrical Technology, 2010, 38(4):31-34.

[7] Zhang Donghui, Feng Xiaodong, Sun Jingqiang, etc. Research of Flexible Cable in DC Transmission in China Southern Power Grid [J]. China Southern Power Grid Techology, 2011, 5(2):1-6.

[8] Hanley T L, Burford R P, Fleming R J. A general review of polymericinsulation for use in HVDC cables [J]. IEEE Electrical Insulation Magazine, 2003, 19(1): 13-24.

[9] Rogti F Mekhaldi A, Laurent C. Space charge behavior at physical interfaces in cross-linked polyethylene under DC field [J]. IEEE Transactions on Dielectrics and Electrical Insulation, 2008, 15(5):1478-1485.

[10] Takeda T, Hozumi N, Suzuki H, et al. Space charge behavior in full-size $250 \mathrm{kV}$ DC XLPE cables [J]. IEEE Transactions on Power Delivery, 1998, 13(1): 28-39.

[11] Han Baozhong, Fu Mingli, Li Chunyang, etc. Influences about Silicone rubber conductivity properties on the HVDC ending electrical field distribution in XLPE [J]. Technical of High Voltage, 2014, 40(9): 2627-2634.

[12] Han Baozhong, Guo Wenmin, Li Zhonghua. Nonlinear Conductivity Properties of Silicon carbide/silicone rubber composite material[J]. Functional Materials, 2008, 39(9): 1490-1493.

[13] Shang Nanqiang. Research about electrical conductivity and dc breakdown characteristics of Nano modified compound liquid silicone rubber [D]. Harbin: Master Thesis of Harbin University of Science and Technology, 2014. [S], 2012. 